\title{
Progress of Intelligent Yarn Spinning Technology in China
}

\author{
Zheng Tianyong* \\ Department of Textile Engineering, Zhongyuan University of Technology, China
}

Submission: September 22, 2017; Published: October 31, 2017

*Corresponding author: Zheng Tianyong, Department of Textile Engineering, Zhongyuan University of Technology, Zhengzhou, 450007, China, Email: zty_zzti@126.com

\begin{abstract}
The paper reviews the history, current situation and prospect of the Intelligent Yarn Spinning (IYS) technology in China, and points that IYS
\end{abstract} is the trend and keep developing in the futrue.

Keywords: Intelligent yarn spinning (IYS); Intelligent management (IM); Digital workshop of yarn spinning

\section{Opinion}

China is the largest country in textile production. There are more than $120 \mathrm{M}$ spinning spindles rotating and producing nearly 19M tons of yarns in the country every year. A dramatic change took place in the past 10 years to China textile industry. Intelligent Yarn Spinning (IYS) technology comes into trend in yarn manufacturing and has been promoted to the trade and stands firm.

\section{Necessity of the intelligent yarn spinning (IYS) technology}

To upgrade the textile industry, increase efficiency, guarantee quality and improve the international competition, the owners of the Chinese textile mills realized that intelligent technology might help them achieve their goals ten years ago. To the owners of the spinning mill, it seems to be more urgent since they face the shortage of workers, increment of wages and high employee turnover rate due to bad workshop environment and strenuous manual labor. From 2012 to 2016, the labor force population has decreased almost 3.65M each year in China [1]. The decrease might get to balance 10 years later. The worse thing is that the younger generation workers would rather not endure the hard work and the bad environment as the elder generation did. The owners of the textile mills have to seek the replacement by intelligent yarn spinning technology.

\section{History}

China government pays much attention to intelligentization of textile industry. As early as in 2001, the 10th five-year development program of China textile industry required that the main textile mills should digitize their manufacturing, designing, management and sales. In 2004, 28 developing fields and 10 key equipment for China textile industry were released. Among them, 4 developing fields were related to digitizing and all the 10 key equipment were related to digitization. Afterwards, the 11st-five year, $12 \mathrm{nd}$-five year and 13rd-five year program are all describing the prospect of intelligentization of the Industry. According to the latest 13rd-five year program, a lot of pilot yarn mills will be set up, realizing automation within whole processes, digital monitoring and management, transporting the materials and semi-products automatically [2]. The labor productivity of the pilot spinning mills with intelligent manufacturing was increased by more than $30 \%$, the production cycle of product development was reduced by more than $20 \%$, the defective product rate decreased by $30 \%$ and the employment dropped to 20 workers/ 10000 spindles.

\section{Characteristics}

Intelligent yarn spinning includes developing and equipping the digitalized machines, monitoring and managing the whole processes automatically. There are 2 aspects to consider:

Continuity of yarn manufacturing processes: The salient characteristics of the IYS system are the continuity of the yarn manufacturing processes, intelligent control of spinning process, intelligent monitoring of workshop environment and automatic distribution of materials and semi-products. By IYS, digital workshop of yarn spinning can be setup, and the goals to satisfy the high quality, high yield, high efficiency, low energy consumption, less labor and reducing the labor intensity 
are achieved. The digital workshop of yarn spinning is the integration of digitization of production equipment, digitization of production process and digitization of management.

PLC controller, counter, LCD screen, servo drives, etc. are widely used in individual digital spinning equipment by mechanical and electrical integration. All the machines are connected by networks to transport information.

An intelligent design has been completed to realize computer aided cotton assorting, arranging of cotton bags, picking and blowing-carding unit, lapping-doubling-combing combined unit, roving-spinning-winding unit, bobbin automatic staking, packaging and warehousing, therefore, less than 30 workers are required for 10000 spinning spindles.

In some systems, unwrapping cotton bale can be automatic. Blow-carding unit is widely applied to reduce the weight irregularity and unevenness of slider. Automatic doffing, automatic inserting roving bobbin, automatic keeping end of roving and transport roving bobbin to spinning frame have been completed successfully on a roving frame. The automatic doffing of ring spinning frame, automatic inserting yarn tube, automatic repiecing and keeping end of yarn, automatically delivering the yarn tube to the automatic winding machine have been completed as well. In an automatic winding machine, automatic bobbin changing, automatic repiecing, automatic guiding end, automatic knotting, automatic inspection of yarn defects and cutting, automatic winding, automatic tube yarn delivery, bobbin automatic sorting has been accomplished.

In jet vortex spinning system and the rotor spinning system, one or more processes in doubling, roving or winding is canceled , therefore, the yarn is produced from the slider to the cone yarn directly, which means the efficiency of spinning can be improved further.

After winding, the cone yarn automatic packaging system shall be prescribed by the automatic weighing machine, automatic bag filling machine, automatic strapping machine, and automatic sealing membrane stack unit. The cones of yarn are accurately weighed by an automatic weighing machine, and then the abnormal tubes are temporarily marked overweight and ultra-light. Automatic sealing bagging machine is used to encapsulate the cones of yarn in plastic film and pack the cones into the yarn bag for transporting or warehousing.

Intelligent management (IM): Intelligent Management (IM) system is an indispensable part of IYS system. IM system changes the original management mode and ideology of running enterprise, therefore, workers, equipment and software system are integrated and interconnected. Usually, IM system mainly consists of data collection, data transmission and system functions. IM automatically realizes the collection of data of spinning equipment, spinning production data of the main auxiliary equipment in real-time, online and offline data of quality, data of workshop environment, data of equipment energy consumption, personnel data, etc., then builds enterprise data platform, ensures the production data sharing between ERP and IM system. System functions of IM include equipment online monitoring, power monitoring, environment monitoring, remote control, production scheduling, order management, equipment management, quality management, energy management and integration with ERP system, etc.

On the basis of advanced sensor technology, communication technology, big data, cloud computing and Internet technology, IM system can issue early warning texts and automatically control equipment operation. Through analyzing the data of equipment operation, production data ,energy consumption online, IM system helps optimize management of enterprise, reduce energy consumption, improve the shortcomings of traditional quality control method, stabilize and improve the quality of products. IM system can also be integrated with ERP to generate reports of production and trace the orders automatically. Customers can easily learn about the real-time order progress and quality of the product through Internet.

As soon as enterprise uses IYS system, the product quality is stable and the consistency is terrific, and the production efficiency has been greatly improved.

\section{Application and effectiveness}

By using IYS technology, spinning efficiency has been improved enormously. In 1987, as many as 360 workers were needed to operate a textile mill with 10000 spindles in China, and the number of workers decreases to 80 in 2016 [3]. To some very modern mills, the number is only 20 . For example in a ring spinning mill of Weiqiao Group, the largest textile mill in the world, 20 workers are required for each 10000 spindles while another textile mill of Ruyi Group needs 15 workers. Huaxing textile mill in Shandong needs only 9 workers, which helps the mill won the first Class Prize 2016 of award for scientific and technological advancement by China National Textile And Apparel Council (CNTAC). Yid a Group sets up a 30000 spindles compact spinning mill at Chang ji in Xinjiang, requires only 45 workers. As for rotor spinning, Litai Silk Road Textile Mill of Jin sheng Group in Xinjiang needs only 6 workers to accomplish the equivalent output. According to the statistics by CNTAC, $2.3 \mathrm{M}$ spindles are totally run under IYS system in 2015 and $24.8 \mathrm{M}$ spindles are equipped with automatic doffing equipment while $5 \mathrm{M}$ spindles are equipped in the roving-spinning-winding unit.

\section{Prospect}

The State Council of China issued "Made in China 2025 strategy" in 2015, aiming to accelerate Intelligent manufacturing engineering and key equipment engineering. Meanwhile, The Belt and Road strategy was put forward. Xinjiang area, as the link connecting China and the mid-Asia, west Asia and Europe, began to develop yarn spinning industry because Xinjiang is the largest cotton producing area and plants the best quality cotton. Due to the strategy of " transmitting the spindle from the east area to 
the west area", yarn mills of 13.6M spindles were setup within 3 years with the encouragement of the government by reducing the taxes and energy costs. Most of the mills are equipped with the latest spinning assembling lines. At the same time, yarn mills at the traditional area have to transform the old machines to the intelligent equipment to adapt the new situation. According to China textile machinery association, the main business revenue of the textile machinery industry was increased by $12.74 \%$ and the total profit was increased by $23.11 \%$ from Jan 2017 to June 2017. It is estimated that $60 \mathrm{M}$ spindles will be equipped on automatic doffing system by 2020 , accounting $50 \%$ of the production capacity. With the increasing of the spinning speed, the number of the total spinning spindles in China might drop below $100 \mathrm{M}$. Even so, according to this trend, yarn spinning industry will still keep developing IYS at high speed for at least 10 years.

\section{Difficulties}

Discontinuity of the some spinning process: Although IYS aims to produce yarn in a continuing production, some processes are interrupted at most IYS system in China. The automatic connections from carding to drawing, from drawing to roving, or from doubling to drawing then to combing seems to be not so important since the labor cost is relative low especially when the enormous investment shall be paid. Automatic Guide Vehicle (AGV) is used as a replacement. Being set by software, AGV will run at the given route carrying semi-products or empty cans or bobbins among the machines. AGV, equipped with infrared obstacle avoidance sensor or ultrasonic obstacle avoidance sensor, is guided by magnetic point navigation control method and Radio Frequency Identification (RFID) technology to ensure the walking precision and the safe performance of the workshop.

Tian men textile machinery co Ltd begin to develop the new drawing frame with double connectors. Several carding machines are connected to a drawing machine by slider cache device, which can isolate the upstream and downstream supply problem caused by the stop between the carding and drawing, and ensure that the carding machine and the drawing machine work well. Similarly, the drawing machine connects the following roving as well [4].

Yarn breakage in spinning: Currently, it is still necessary to deal with the yarn breakage of ring spinning machine manually, especially when it is a must to guide the yarn through the ring, the guide and yarn hook. The piecing procedure is still to complicate and the automatic piecing is not yet realized. That is why the amount of labor used in ring spinning is three to four times higher than rotor spinning and vertex spinning. It is key technique to solve if the efficiency of ring-spin technology to be improved. If the technique is realized, the true unmanned workshop will appear within 5 years.

\section{Conclusion}

Applying intelligent yarn spinning technology represents the general trend, which helps China keep its preponderance in producing yarn. China has made a great achievement in intelligent yarn spinning technology, and the yarn spinning industry will keep its development at high speed for at least 10 years.

\section{References}

1. YAO Mu (2016) The present situation and prospect of intelligent textile industry. Cotton Textile Technology 44(2): 1-3.

2. Hu Guangmin (2016) Construction thinking and practice of intelligent spinning system. Cotton Textile Technology 44(11): 32-35.

3. Zhang Yueping (2017) Design concept and case analysis of digital spinning factory. Cotton Textile Technology 45(5): 71-75.

4. Textile industry development plan (2016-2020).

\section{Your next submission with Juniper Publishers} will reach you the below assets

- Quality Editorial service

- Swift Peer Review

- Reprints availability

- E-prints Service

- Manuscript Podcast for convenient understanding

- Global attainment for your research

- Manuscript accessibility in different formats ( Pdf, E-pub, Full Text, Audio)

- Unceasing customer service

Track the below URL for one-step submission https://juniperpublishers.com/online-submission.php 